\title{
Chk1 Inhibitor GDC-0425
}

National Cancer Institute

\section{Source}

National Cancer Institute. Chk1 Inhibitor GDC-0425. NCI Thesaurus. Code C116756.

An orally bioavailable inhibitor of checkpoint kinase 1 (chk1), with potential antineoplastic and chemosensitization activities. Upon oral administration, chk1 inhibitor GDC-0425 selectively binds to chk1, thereby preventing activity of chk1 and abrogating the repair of damaged DNA. This may lead to an accumulation of damaged DNA, inhibition of cell cycle arrest, and induction of apoptosis. GDC-0425 may potentiate the cytotoxicity of DNA-damaging agents and reverse tumor cell resistance to chemotherapeutic agents. Chk1, an AT P-dependent serine/threonine kinase, mediates cell cycle checkpoint control, is essential for DNA repair, and plays a key role in resistance to chemotherapeutic agents. 